\title{
Los periódicos en la Andalucía de principios del siglo XIX: Guerra, opinión pública y sociedad
}

\author{
Juan Jesús Bravo CARO \\ Universidad de Málaga \\ jjbravo@uma.es
}

\begin{abstract}
Resumen
La prensa conoce un impulso de indudable trascendencia en la España del final del Antiguo Régimen. La Guerra de la Independencia y la necesidad de los contendientes por difundir las victorias frente al enemigo abrirán una nueva etapa, donde los periódicos editados en el área del sur peninsular tendrán un gran protagonismo en la conformación de la opinión pública. Las noticias del conflicto, las informaciones de carácter nacional o internacional, junto a diversos datos referidos a la vida cotidiana de las ciudades, tendrán su acogida en las páginas de los diarios y semanarios publicados.
\end{abstract}

Palabras clave: Prensa, Guerra de la Independencia, Andalucía.

The newspapers in the Andalusia of beginning of the 19th century: War, public opinion and society

\begin{abstract}
Mass media will be going to know a momentum of undoubted importance in the Spain of the end of the old regime. The war of independence and the necessity of the contenders to disseminate victories against the enemy, will open a new stage, where the newspapers edited in the area south of the peninsula will have a major role in the conformacion of the public opinion. The news of the conflict, the national or internacional information and other details regarding the everyday life of the citizens, will have their reception in the pages of newspapers and weeklies published.
\end{abstract}

Key Words: Press, War of the Independence, Andalucía.

\section{Referencia normalizada:}

Bravo Caro, J. J. (2013) Los periódicos en la Andalucía de principios del siglo XIX: Guerra, opinión pública y sociedad. Historia y Comunicación Social. Vol. 18 Nº Especial Octubre. Págs. 529-539.

Sumario: 1. Introducción. 2. El conflicto como motor de la expansión de la prensa en España. 3. Los periódicos andaluces durante la Guerra de la Independencia. 4. Conclusiones. Referencias bibliográficas.

\section{Introducción}

La prensa del tránsito del Antiguo Régimen a la Edad Contemporánea facilitará unas inestimables posibilidades para el estudio de la Historia. A partir de las noticias incluidas en los diferentes periódicos de la época podemos acercarnos a unas fuentes complementarias, en el sentido de contenido no de rango de importancia, de las puramente archivísticas. No hacía falta mentir, ni falsear la verdad. Así lo manifestaba, en 
cierto modo, el Atalaya Patriótico de Málaga, el 11 de febrero de 1809: no todo debe decirse a todos, ni en todos tiempos y circunstancias; y que es menester manejar con mucho tino y delicadeza la opinión pública para sacar buen partido, por que muchas veces ella decide la suerte de las naciones.

La utilización de ese medio permitía, antes como ahora, destacar sólo las informaciones relativas a uno de los bandos contendientes, el afín al de la editorial, y los Estados pusieron toda su maquinaria posible para desplegar un seguimiento de los contenidos o, incluso, limitar el acceso a la información (Albert, 1990: 41-43 y 61-63). Esa incipiente opinión pública surgida de los acontecimientos vividos en la España de principios del siglo XIX debía ser moldeada, por otra parte ya de por si mediatizada al constituirse en el seno de una sociedad profundamente analfabeta, y sujeta a controversias o interpretaciones, con un margen mínimo de búsqueda particular del conocimiento.

En el caso de la Guerra de la Independencia, el análisis del conflicto propiciará una vasta producción historiográfica (De Diego, 2010), en la que los aspectos derivados o inherentes a las ediciones de este medio de comunicación y difusión han ocupado un lugar destacado en los últimos años. Prueba de ello son los artículos de revistas, cuando no números monográficos de las mismas (Historia y Comunicación Social, 14, 2009), contribuciones en Congresos o monografías sobre el tema, según iremos mencionando a lo largo del presente trabajo.

En este sentido, las diversas jurisdicciones que en esos años configuraban la actual Comunidad Autónoma de Andalucía tendrán una relevancia fundamental, como campo de batalla a la vez de origen de noticias trascendentales en el devenir histórico de España. La prensa será un instrumento de inestimable valor, y ha generado la base de una multitud de investigaciones específicas, entre las que destacan las de Cuenca Toribio (1975), Checa Godoy (2009), Díaz Domínguez (2009), Gallego Burín (1990) y Gómez Ímaz (2008). Todas ellas han sido consultadas a la hora de elaborar el presente artículo, junto a referencias de cuestiones concretas, de aspectos muy significativos en el desarrollo de esta otra arma utilizada por los grupos en lucha. Los textos de los diarios, semanarios y cualquier tipología periodística de aquellos años han servido para completar el panorama recogido en nuestras páginas.

\section{El conflicto como motor de la expansión de la prensa en España}

Las famosas abdicaciones de Bayona inauguraban una etapa de inestabilidad política y social en el seno de la España peninsular, cuyas repercusiones más inmediatas tuvieron fiel reflejo en la proliferación de periódicos en uno y otro sentido de las decisiones adoptadas (Arrabat, 2008). El esfuerzo por potenciar y contrarrestar, al mismo tiempo, las actuaciones de los bandos que se formaron a raíz de la entrada de tropas galas en territorio español, y la proclamación de José Bonaparte como monarca en sustitución de Fernando VII, contaría con un elemento material cada vez más impres- 
cindible: la prensa. Ésta ya había contribuido a las labores de propaganda y formación de opinión pública en otros países, pero en España el conflicto armado llevado a cabo entre 1808 y 1814 favorecería un nuevo escenario donde iniciar y fortalecer un despegue nada desdeñable. De hecho, ciertos autores coinciden en indicar un antecedente inmediato en suelo hispano, de marcada influencia pro-francesa y con la intención clara de debilitar la monarquía de los Borbones. Nos referimos a la Gaceta de Madrid, durante el quinquenio 1804-1808 y cuyas consecuencias estuvieron, al final, muy alejadas del espíritu inicial de presentar la exaltación de un modelo de gobierno galo en contraposición a los males de la España bajo el reinado de Carlos IV (Larriba, 2008: 275-276). No obstante, la proliferación llegó a ser criticada en fases históricas posteriores, hasta el punto de advertir de lo pernicioso y peligroso de su existencia (Centinela contra periódicos, 1820): Ahora que nos amenaza un grave mal por los papeluchos que se imprimen, era muy justo que saliese un Centinela contra periódicos, que avise del mal que estos pueden ocasionar...

La Guerra de la Independencia en España tuvo una dimensión internacional, como no podía ser de otra manera, dadas las características y el contexto en el que se produjo. También en esta cuestión la prensa va a mostrar el interés por difundir las noticias dentro y fuera de nuestras fronteras, para lo cual determinados periódicos de ciertas naciones destacarán corresponsales al objeto de recabar la información más directa sobre las acciones bélicas y políticas (Durán de Porras, 2009 y 2008: 879), e incluso trasladar a los periódicos españoles las noticias editadas en otras latitudes (Gazeta Diaria de Londres (en Sevilla)... Año de 1813) al considerar la inexactitud, retraso o falsedad de las propagadas en España.

Con anterioridad a 1808 la preocupación por atender a la construcción de una opinión pública cercana al poder que la genera tiene ejemplos en algunos países europeos (Bauer, 2009; Habermas, 2002), aunque en España será durante la segunda mitad del setecientos cuando se inicien los primeros síntomas de este proceso (De La Nogal Fernández, 2006).

De esta manera, la prensa deberá dar respuesta a los retos planteados por aquellos que manifestaron primero la oposición armada frente al enemigo, para después pasar a la actividad de consolidar un marco jurídico-político común para el conjunto de la sociedad, una vez alcanzada la deseada victoria. Llegarán a sucederse, cuando no a convivir, una prensa que podría considerarse claramente de guerra (Gil Novales, 2008: 334) y otra con un marcado perfil político, bajo la atenta mirada no de los censores como en una etapa muy reciente al estallido de la lucha, pero de indudables intereses manifestados en las líneas editoriales que veían la luz (Coca Ramírez, 2006; Rodríguez Gutiérrez, 2006). Camino todavía bastante lejano y complejo hasta desembocar la prensa de opinión en una de información de décadas posteriores. Los obstáculos fueron variados, máxime en una fase de confrontación, y tras la conquista de medidas tendentes a conseguir una libertad de imprenta plena (La Parra López, 1984; Mira Benavent, 1995; Fernández Segado, 2004; Magdaleno Alegría, 2008 y 2013), y la profesionalización paulatina de los escritores (Sánchez Hita, 2009). De igual forma, pudieron apreciarse modificaciones en el tratamiento de temas muy 
concretos en los años de la contienda, destacando lo relativo a la visualización de la mujer al traspasar el ámbito privado tradicional y apareciendo en el público, mediante la participación activa en las labores de difusión de las noticias (Cantos Casenave, 2008 y 2010; Sánchez Hita, 2010), aunque su actividad estuvo a veces mediatizada o adquirió un carácter efímero (García López, 2011: 35-39). Sin olvidar el recurso de la caricatura como elemento sugerente a la hora de formar la opinión pública (De Diego, 2008), utilizada con más extensión en las décadas sucesivas (Arcas Cubero, 1990).

Por tanto, la propaganda a través de los periódicos se erigió como un punto de especial notabilidad, con cambios a lo largo del periodo (Pizarroso Quintero, 2008; Martín de la Guardia, 2011). Tanto los foráneos como los autóctonos pudieron percibir el viraje de esa propaganda inicial, transcurridos los primeros momentos de enfrentamiento contra los franceses, para convertirse en un arma de confrontación entre liberales y tradicionalistas (Caldevilla Domínguez, 2011: 26). Así, guerra, opinión pública y sociedad marcharon de la mano durante esos años, pues el conflicto, el tratamiento dado al mismo en las páginas de los periódicos, debía conformar una opinión pública incondicional y participativa en los acuerdos adoptados en el seno de las instituciones más importantes - las Cortes de Cádiz, por encima de todas-, cuya consecuencia más ansiada era alcanzar un gobierno justo para toda la comunidad que había resistido la agresión de los franceses.

\section{Los periódicos andaluces durante la Guerra de la Independencia}

Los territorios meridionales españoles de la Península Ibérica recibirán la atenta mirada, no solo del resto de España si no también de países más allá de los Pirineos. En especial, la capital gaditana adquirirá un protagonismo por encima de las demás ciudades (Sánchez Hita, 2006; Díaz Dota, 2009), cuando se inicie allí un periodo constituyente que desembocará en la Carta Magna que sirve de referencia para las siguientes de ese mismo siglo y del XX.

Las obras que se han detenido en analizar esa etapa son numerosas, como hemos señalado más arriba, aunque en los últimos años la historiografía sobre la materia ha aumentado considerablemente. Coinciden los trabajos en situar en los años del conflicto hispano-francés, en suelo peninsular, el momento de despegue y referencia de una prensa andaluza posterior más diversificada (García Galindo, 2007). No todas las localidades llegarían a editar periódicos propios, pero muchos de ellos conocerán un impulso a partir de 1808. Las urbes extremas geográficamente permanecerán sin prensa propia hasta 1810 (Checa Godoy, 1990; Gerez Valls, 2006; Díaz Domínguez, 2013), mientras Cádiz aglutinará más del $50 \%$ de los periódicos con tirada en el área andaluza, y a una gran distancia Granada y Málaga (Díaz de Escovar, 2000). Córdoba y Jaén no tendrán un gran protagonismo en este campo (Checa Godoy, 1986 y 2010), y ciertos núcleos de población asistirán al tímido advenimiento de diarios 
(De La Plata, 2010). La frenética actividad política desplegada desde 1812 en la urbe gaditana explica esa descompensación entre localidades, y el eco desigual en la prensa producida (Sánchez Hita, 2007), aunque la cantidad concreta de títulos sea cuestionada (Seoane, 1983: 41). La prensa implantaba un nuevo vehículo de gran valor a la hora de difundir las temáticas tratadas en las Cortes (Durán López, 2008), y lo político trascendía en una nueva dimensión hacia lo público (Romero Ferrer, 2008: 291).

La nómina de cabeceras es abundante, y obedecen a planteamientos y enfoques políticos diversos, incluso dentro de la línea contraria al establecimiento del gobierno galo, con un predominio claro de los de corte liberal. El desencuentro de muchos de esos periódicos queda patente en el Testamento del Abeja Española (Cantos Casenave, 2006) publicado el 31 de agosto de 1813.

Por regla general, se trataba de ejemplares con dimensiones reducidas, de formato pequeño, alrededor de 4 páginas, aunque podían llegar a superar las 8 al incluir suplementos adicionales. Distribuidos en imprentas, librerías o puntos de venta específicos, mantenían un precio similar, en función de las características de cada uno de ellos (Sánchez Hita, 2008), y se recurría a la fórmula de la suscripción trimestral, sobre todo, para abaratar la adquisición particular, con un recargo adicional si debían enviarlo fuera del lugar de edición. Nos podemos encontrar con diarios o gacetas que mantienen la misma cabecera pese a imprimirse en épocas bajo dominio de José I o "liberada" la localidad. Un ejemplo sería la Gazeta de Sevilla, bisemanal (martes y viernes), claramente bonapartista hasta 1812, y desde la salida del ejército francés de la capital hispalense cambia de tendencia para erigirse una fase fernandina. En otras ocasiones, los periódicos desaparecen físicamente aunque sus fines y contenidos son trasladados a lugares cercanos bajo la misma autoridad, una vez expulsados del origen. Caso de la Gazeta Ministerial de Sevilla y la Gazeta de Ayamonte (Saldaña Fernández, 2006; Díaz Domínguez, 2009).

Desde 1808 hasta 1812 no menos de diez diarios verían la luz en las jurisdicciones andaluzas, duplicándose el número en el bienio siguiente. Checa Godoy (2011: 665-666) señala los rasgos principales de los mismos, y diferencia entre los oficiales - Diario de Granada, Diario de Jaén, Diario de Málaga, Diario de las Cortes, Diario del gobierno de Granada, Diario del gobierno de Sevilla...-, liberales, ya fuera patriótico o exaltado - El Conciso, El Espectador sevillano, El Publicista, El Imparcial, Gazetilla nocturna, Diario Crítico y Erudito de Granada...-, absolutistas - Diario de la Tarde, El Procurador general de la nación y el rey, Diario Crítico de Sevilla, Diario Patriótico, Directorio eclesiástico y político de Sevilla, Mercurio gaditano...-, o meramente informativos - Diario mercantil y político de Málaga, Diario redactor de Sevilla, Diario gaditano...-.

Los diarios iniciaban sus cabeceras con el santoral, para a continuación recoger las noticias agrupadas en nacionales y extranjeras, siempre en consonancia a la línea editorial. Se trataba de crónicas breves, destacando los hechos más relevantes de su 
bando, y las pérdidas o derrotas del enemigo, en el campo de batalla peninsular y europeo.

El desarrollo de las operaciones militares cobraba un gran protagonismo en los artículos, con inclusión de supuestas cartas remitidas por algunos soldados a sus familiares, dando cuenta de la equivocación de continuar la lucha, y el buen tratamiento recibido por sus captores (Diario de Málaga, 23 de agosto de 1808), o alentando a alistarse en los cuerpos de ejército, como lo recogido en Suplemento al Correo de Jaén (29 de marzo de 1809): Ahora más que nunca, españoles, necesita el Exército de nuevos escuadrones, que saliendo del centro de sus familias vayan como leones furiosos á despedazar á esos lobos carniceros que intentan vilmente devorarlas. Igualmente, figuraba la divulgación de acuerdos realzando aquellas cuestiones más importantes para la conformación de los intereses comunes. Al respecto es muy ilustrativo un párrafo del Atalaya Patriótico de Málaga (octubre - 1809) cuando afirma que el nuevo sistema de gobierno es una tarea ardua en la cual

Los periodistas y los sabios deben suplir interinamente, procurando en sus escritos rectificar las ideas, ilustrar al Público y mostrarles y facilitarles la senda, por donde, venerando siempre la Religión santa, respetando las Leyes y Magistrados, y conservando el santo decoro y pudor de la costumbre, sin la quales son inútiles las Leyes y los Gobiernos, puedan sostener sus derechos, subir al templo de las glorias de sus mayores, y adquirirse un nombre respetable y temido entre las Naciones de Europa.

Junto a lo expuesto, también insertaban noticias de un plano que podíamos considerar más social o de vida cotidiana (Ramos Santana, 2008), pues los periódicos se van a convertir en el escaparate donde poder visualizar aspectos específicos de las localidades de impresión. Así tenemos en capitales marítimas el tráfico de barcos de sus puertos, y de otros cercanos, lo cual permite aproximarnos a los precios de determinados productos desembarcados en el litoral andaluz, preferentemente Cádiz y Málaga (Diario Mercantil de Cádiz, sábado 17 de junio de 1809). Sin olvidar, el recurso a anunciar algún tipo de diversión colectiva (Román López, 2008), o avisos de perfil profesional (Diario de Sevilla, domingo 31 de diciembre de 1809): Aviso. Doña Isidoro Pinto del Rey, comadre aprobada por el cirujano de Madrid, discípula del real colegio de S. Carlos, y ayudante de partos del real colegio de desamparados de la misma villa, avisa al público su residencia en esta ciudad en la calle de Odreros junto á la plazuela de la Alfalfa núm. 24, deseosa de que la ocupe, y de complacerle.

\section{Conclusiones}

Aunque de manera breve, hemos presentado el panorama de la prensa andaluza durante el conflicto de 1808-1814. La Guerra de la Independencia ofreció la oportunidad de utilizar a los periódicos como vehículos de propaganda, construcción de la opinión pública e instrumento de difusión de los acuerdos adoptados en el seno de las instituciones encargadas de dirigir los destinos militares y políticos de los conten- 
dientes. Pese a la desigualdad en cuanto al número de títulos editados en las diversas zonas jurisdiccionales al sur de Despeñaperros, una serie de elementos comunes conformaron líneas editoriales similares, en donde tuvieron cabida los temas indicados, y la agregación de materias de carácter económico con alcance general, y otras mucho más cercanas al ámbito de lo particular, en sus variadas fórmulas (Moreno Sardá, 1986: 158-159). Por encima de todas las ciudades destacaría Cádiz, en base al protagonismo político delegado, y en un segundo plano, en función de los años tratados, la capital hispalense. Los acontecimientos hispanos puramente militares eran alternados con las noticias llegadas de más allá de las fronteras, conformando una información mediatizada en parte, pero muy sugestiva a la hora de realizar investigaciones de carácter histórico. El desarrollo de la prensa ya no se detendría, aunque a lo largo de todo el siglo XIX y el siguiente conocería las inevitables consecuencias de una sucesión de gobiernos de diferentes signo, que no siempre contribuyeron a la existencia de periódicos liberados de la presión estatal, como lo apreciado en países europeos o al otro lado del Atlántico, con un recorrido institucional, profesional y económico mayor.

\section{Referencias bibliográficas}

ALBERT, P. (1990). Historia de la prensa. Madrid: Rialp.

ARCAS CUBERO, F. (1990). El País de la Olla: la imagen de España en la prensa satírica malagueña de la Restauración. Málaga. Arguval.

ARRABAT, R. (2008). La propaganda política en la Guerra. En: Revista HMIC: Història Moderna i Contemporània, $\mathrm{n}^{\circ}$ 6, Barcelona: UAB. p. 26-42.

BAUER, W. (2009). La opinión pública y sus bases históricas. Santander. Univ. de Cantabria.

CALDEVILLA DOMÍNGUEZ, D. (2011). Las independencias americanas: historiografía, prensa e identidad criolla. En: Historia y Comunicación Social, $\mathrm{n}^{\mathrm{o}} 16$, Madrid: UCM. p. 13-31.

CANTOS CASENAVE, M. (2006). "La importancia de la opinión pública en el periódico la Abeja Española". En CANTOS CASENAVE, M. (ed.) (2006). Redes y espacios de opinión pública. De la Ilustración al Romanticismo. Cádiz, América y Europa ante la Modernidad. 1750-1850. Cádiz. Univ. de Cádiz. p. 123-136. (2008). "Las mujeres en la prensa entre la Ilustración y el Romanticismo". En CANTOS CASENAVE, M.; DURÁN LÓPEZ, F. y ROMERO FERRER, A. (eds.) (2008). La guerra de pluma. Estudios sobre la prensa de Cádiz en el tiempo de las Cortes (1810-1814). Tomo III. Sociedad, consumo y vida cotidiana. Cádiz. Univ. de Cádiz. p. 161-336.

(2010). "La Literatura femenina en la Guerra de la Independencia: A la ciudadanía por el patriotismo". En: Revista HMIC: Història Moderna i Contemporània, $\mathrm{n}^{\circ} 8$, Barcelona: UAB. p. 33-47. 
COCA RAMÍREZ, F. (2006). "Palabras escritas. En torno a la opinión pública en el periódico gaditano El Conciso (1810-1814)". En CANTOS CASENAVE, M. (ed.) (2006). Redes y espacios de opinión pública... p. 137-148.

CUENCA TORIBIO, J. M. (1975). "Fuentes periodísticas para el estudio de la Guerra de la Independencia". En: Cuadernos de Historia Jerónimo Zurita, no 25-26, Zaragoza: IFC. p. 141-175.

CHECA GODOY, A. (1986). Historia de la prensa jiennense, 1808-1983. Jaén: Diputación Provincial.

(1990). Los orígenes y el primer desarrollo de la prensa en Huelva (1810-1874). Huelva.

(2009). La prensa española durante la Guerra de la Independencia (1808-1814). Cádiz: Quórum.

(2010). Historia de la Prensa en Córdoba (1790-2010). Córdoba: Asociación de la Prensa de Córdoba.

(2011). Historia de la prensa andaluza. Sevilla: Junta de Andalucía - Ediciones Alfar.

DE DIEGO, E. (2008). "España: 1808-1814. La propaganda como herramienta en la formación de la opinión pública: la caricatura". En MIRANDA RUBIO, F. (coord.) (2008). Congreso Internacional Guerra, sociedad y política (1808-1814). Volumen I. Pamplona: Gobierno de Navarra - Univ. Pública de Navarra. p. 209-232. (2010). "La Guerra de la Independencia: un balance en su Bicentenario". En: Cuadernos de Historia Moderna. Anejos, IX, Madrid: UCM. p. 212-253.

DE LA NOGAL FERNÁNDEZ, R. (2006). Construyendo espacios. Los papeles periódicos y la organización de la sociedad española a finales del Antiguo Régimen. Madrid: UAM.

DE LA PLATA, J. (2010). Historia del periodismo en Jerez de la Frontera, 18002010. Jerez (de la Frontera): Cofran.

DÍAZ DE ESCOVAR, N. (2000). Bibliografía de la prensa malagueña. Apuntes para la historia del periodismo en la provincia de Málaga. Granada.

DÍAZ DOMÍNGUEZ, M. P. (2009). "La introducción de la prensa escrita en la vida de los onubenses durante la Guerra de la Independencia: la Gazeta de Ayamonte". En CUENCA TORIBIO, J. M. (coord.) (2009). Andalucía en la Guerra de la Independencia (1808-1814). Córdoba: Univ. de Córdoba. p. 347-354.

(2013). De las gazetas a la prensa digital: dos siglos de periodismo escrito en Huelva (1810-2010). Huelva: Univ. de Huelva.

DÍAZ DOTA, M. Á. (2009). "La prensa absolutista y sus crónicas de Cortes en el Cádiz del periodo constituyente: El Diario de la Tarde y su forma de expresión". En RAMOS SANTANA, A. y ROMERO FERRER, A. (eds.) (2009). 1808-1812. Los emblemas de la libertad. Cádiz. Univ. de Cádiz. p. 203-225.

DURÁN DE PORRAS, E. (2008). "Corresponsales británicos en la Guerra de la Independencia: la batalla de la información”. En MIRANDA RUBIO, F. (coord.) (2008). Congreso Internacional Guerra, sociedad y política... Volumen II... p. 879-901. 
(2009). "Ecos de la batalla de Bailén en la prensa inglesa". En CUENCA TORIBIO, J. A. (ed.) (2009): Andalucía en la Guerra de la Independencia (1808-1814). Córdoba: Univ. de Córdoba. p. 355-363.

DURÁN LÓPEZ, F. (2008). "Diputados de papel: la información parlamentaria en la prensa de la etapa constituyente (septiembre de 1810 - marzo de 1812)". En CANTOS CASENAVE, M.; DURÁN LÓPEZ, F. y ROMERO FERRER, A. (eds.) (2008). La guerra de pluma ... Tomo II. Política, propaganda y opinión pública... p. 37-235.

FERNÁNDEZ SEGADO, F. (2004). "La libertad de imprenta en las Cortes de Cádiz". En: Revista de Estudios Políticos (Nueva Época), nº. 124, abril-junio, Madrid: CEPC. p. 29-54.

GALLEGO BURIN, A. (1990). Granada en la Guerra de la Independencia. Los periódicos granadinos en la Guerra de la Independencia. Granada: Univ. de Granada.

GARCÍA GALINDO, J. A. (2007). "Historia de los medios de comunicación en Andalucía: un balance historiográfico". En CHECA GODOY, A.; ESPEJO CALA, C. y RUIZ ACOSTA, M. J. (coords.) (2007). ABC de Sevilla. Un diario y una ciudad. Análisis de un modelo de periodismo local. Sevilla: Univ. de Sevilla. p. 343-360.

GARCÍA LÓPEZ, A. B. (2011). "La participación de las mujeres en la independencia hispanoamericana a través de los medios de comunicación". En: Historia y Comunicación Social, $\mathrm{n}^{\circ}$ 16, Madrid: UCM. p. 33-49.

GEREZ VALLS, F. (2006). Los diarios almerienses del siglo XIX. La prensa en la provincia de Almería, 1823-2000. Almería: Asociación de Periodistas - Asociación de la Prensa de Almería.

GIL NOVALES, A. (2008). "Estado de la cuestión sobre la prensa de la época". En MIRANDA RUBIO, F. (coord.) (2008): Congreso Internacional Guerra, sociedad y política (1808-1814). Volumen I... p. 325-354.

GÓMEZ ÍMAZ, M. (2008). Los periódicos durante la Guerra de la Independencia [1808-1814]. Prólogo de Manuel Moreno Alonso. Sevilla: Centro de Estudios Andaluces - Editorial Renacimiento.

HABERMAS, J. (2002). Historia y crítica de la opinión pública: la transformación estructural de la vida pública. Barcelona: Gustavo Gili.

LA PARRA LÓPEZ, E. (1984). La libertad de prensa en las Cortes de Cádiz. Valencia: NAU Llibres.

LARRIBA, E. (2008). "La contribución de la Gaceta de Madrid al desprestigio de Carlos IV y del Antiguo Régimen por la exaltación de Napoleón (1804-1808)". En: Cuadernos de Historia Moderna. Anejos, VII, Madrid:UCM. p. 239-276.

MAGDALENO ALEGRÍA, A. (2008). "El origen de la libertad de imprenta en España". En MIRANDA RUBIO, F. (coord.) (2008). Congreso Internacional Guerra, sociedad y politica .... Volumen II... p. 1007-1026.

(2013). "La libertad de imprenta como premisa de la primera constitución racional-normativa española: la Constitución de Cádiz de 1812”. En Revista de Derecho Político, no 87, Madrid: UNED. p. 223-252. 
MARTÍN DE LA GUARDIA, R. M. (2011). "Armas de papel. Prensa y propaganda en la Guerra de la Independencia". En La Guerra de la Independencia en el mosaico peninsular (1808-1814). Burgos: Univ. de Burgos. p. 451-472.

MIRA BENAVENT, J. (1995). Los límites penales a la libertad de expresión en los comienzos del régimen constitucional español. Valencia: Tirant lo Blanch.

MORENO SARDÁ, A. (1986). "«Realidad Histórica» y «realidad informativa»: la re-producción de la realidad social a través de la prensa". En GARITAONANDIA GARNACHO, C. y TUÑÓN DE LARA, M. (coords.) (1986). La prensa en los siglos XIX y XX: metodología, ideología e información. Aspectos económicos y tecnológicos. Bilbao: Univ. del País Vasco. p. 145-163.

PIZARROSO QUINTERO, A. (2008). "Apuntes sobre la propaganda de guerra, 1808-1814”. En CANTOS CASENAVE, M.; DURÁN LÓPEZ, F. y ROMERO FERRER, A. (eds.) (2008). La guerra de pluma ... Tomo II. Política, propaganda y opinión pública.... p. 19-36.

RAMOS SANTANA, A. (2008). "La vida cotidiana en el Cádiz de las Cortes: el recurso a la prensa como fuente para su estudio". En CANTOS CASENAVE, M.; DURÁN LÓPEZ, F. y ROMERO FERRER, A. (eds.) (2008). La guerra de pluma ... Tomo III. Sociedad, consumo y vida cotidiana... p. 21-101.

RODRÍGUEZ GUTIÉRREZ, M. (2006). "Estrategias del Procurador general de la nación y del rey en el debate de la opinión pública". En CANTOS CASENAVE, M. (ed.) (2006). Redes y espacios de opinión pública... p. 149-158.

ROMÁN LÓPEZ, M. (2008). "El Cádiz de 1811: la vida cotidiana a través del Diario Mercantil". En CANTOS CASENAVE, M.; DURÁN LÓPEZ, F. y ROMERO FERRER, A. (eds.) (2008). La guerra de pluma... Tomo III. Sociedad, consumo y vida cotidiana... p. 103-157.

ROMERO FERRER, A. (2008). “'Los serviles y liberales o la guerra de los papeles'. La Constitución de Cádiz y el teatro". En CANTOS CASENAVE, M.; DURÁN LÓPEZ, F. y ROMERO FERRER, A. (eds.) (2008). La guerra de pluma... Tomo II. Política, propaganda y opinión pública... p. 287-365.

SALDAÑA FERNÁNDEZ, J. (2006): "La prensa en el suroeste peninsular durante la Guerra de la Independencia: la Gazeta de Ayamonte como vehículo de expresión de la Junta Suprema de Sevilla". En CANTOS CASENAVE, M. (ed.) (2006). Redes y espacios de opinión pública... p. 185-200.

SÁNCHEZ HITA, B. (2006). "El traslado de las Cortes de Cádiz y su repercusión en la prensa". En CANTOS CASENAVE, M. (ed.) (2006): Redes y espacios de opinión pública... p. 159-183.

(2007). "La prensa en Cádiz durante la Guerra de la Independencia: corpus y propuesta de periodización”. En RAMOS SANTANA, A. (coord.) (2007). Lecturas sobre 1812. Cádiz. Ayunt. de Cádiz - Univ. de Cádiz. p. 261-273.

(2008). "Cuánto cuesta la opinión pública: precios, densidad y periodicidad de la prensa gaditana (1808-1814)". En CANTOS CASENAVE, M.; DURÁN LÓPEZ, F. y ROMERO FERRER, A. (eds.) (2008). La guerra de pluma... Tomo III. Sociedad, consumo y vida cotidiana... p. 337-454. 
(2009). "Los espectadores-pensadores y su influencia en la prensa gaditana del siglo XVIII y la Guerra de la Independencia: un modelo de éxito en una sociedad cambiante". En: Cuadernos Dieciochistas, n 9, Salamanca: Univ. de Salamanca. p. 219-246.

(2010). "Las escritoras en la prensa de la Guerra de la Independencia vistas por sus colegas: ¿lucha de género o política?". En: Revista HMIC: Història Moderna $i$ Contemporània, $\mathrm{n}^{\mathrm{o}}$ 6, Barcelona: UAB. p. 117-139.

SEOANE, M. C. (1983). Historia del periodismo en España, II. El siglo XIX. Madrid: Alianza Editorial.

\section{El autor}

Juan Jesús Bravo Caro es Doctor en Filosofía y Letras (Historia), por la Universidad de Málaga. Profesor Titular de Historia Moderna y Director del Departamento de Historia Moderna y Contemporánea en la citada institución. Autor de varias monografías, artículos de revistas y capítulos de libros en diversos países, centra su línea de investigación principal en la sociedad del Antiguo Régimen de la Monarquía hispánica, tanto en la España peninsular como en los territorios americanos o mediterráneos bajo su soberanía. 